\title{
Effects of Pressure Support Ventilation May Be Lost at High Exercise Intensities in People with COPD
}

\section{David Anekwe, Michel de Marchie \& Jadranka Spahija}

To cite this article: David Anekwe, Michel de Marchie \& Jadranka Spahija (2017) Effects of Pressure Support Ventilation May Be Lost at High Exercise Intensities in People with COPD, COPD: Journal of Chronic Obstructive Pulmonary Disease, 14:3, 284-292, DOI: 10.1080/15412555.2017.1304533

To link to this article: https://doi.org/10.1080/15412555.2017.1304533

Published online: 07 Apr 2017.

Submit your article to this journal $\square$

山 Article views: 188

Q View related articles 두

View Crossmark data $־$

Citing articles: 1 View citing articles $\asymp$ 


\title{
Effects of Pressure Support Ventilation May Be Lost at High Exercise Intensities in People with COPD
}

\author{
David Anekwe ${ }^{a, b, c}$, Michel de Marchie $^{d}$, and Jadranka Spahija ${ }^{a, b, c}$ \\ ${ }^{a}$ School of Physical and Occupational Therapy, McGill University, Montreal, Quebec, Canada; ${ }^{b}$ Research Center, Sacré-Coeur Hospital, Montreal, \\ Quebec, Canada; 'Center for Interdisciplinary Research in Rehabilitation in Montreal, Jewish Rehabilitation Hospital, Laval, Quebec, Canada; \\ ${ }^{\mathrm{d}}$ Department of Adult Critical Care, Jewish General Hospital, Montreal, Quebec, Canada
}

\begin{abstract}
Pressure support ventilation (PSV) may be used for exercise training in chronic obstructive pulmonary disease (COPD), but its acute effect on maximum exercise capacity is not fully known. The objective of this study was to evaluate the effect of $10 \mathrm{~cm} \mathrm{H}$ O PSV and a fixed PSV level titrated to patient comfort at rest on maximum exercise workload (WLmax), breathing pattern and metabolic parameters during a symptomlimited incremental bicycle test in individuals with COPD. Eleven individuals with COPD (forced expiratory volume in one second: $49 \pm 16 \%$; age: $64 \pm 7$ years) performed three exercise tests: without a ventilator, with $10 \mathrm{~cm} \mathrm{H} \mathrm{H}_{2} \mathrm{O}$ of PSV and with a fixed level titrated to comfort at rest, using a SERVO-i ventilator. Tests were performed in randomized order and at least 48 hours apart. The WLmax, breathing pattern, metabolic parameters, and mouth pressure (Pmo) were compared using repeated measures analysis of variance. Mean PSV during titration was $8.2 \pm 4.5 \mathrm{~cm} \mathrm{H}_{2} \mathrm{O}$. There was no difference in the WLmax achieved during the three tests. At rest, PSV increased the tidal volume, minute ventilation, and mean inspiratory flow with a lower end-tidal $\mathrm{CO}_{2}$; this was not sustained at peak exercise. Pmo decreased progressively (decreased unloading) with PSV at workloads close to peak, suggesting the ventilator was unable to keep up with the increased ventilatory demand at high workloads. In conclusion, with a Servo-i ventilator, $10 \mathrm{~cm} \mathrm{H}_{2} \mathrm{O}$ of PSV and a fixed level of PSV established by titration to comfort at rest, is ineffective for the purpose of achieving higher exercise workloads as the acute physiological effects may not be sustained at peak exercise.
\end{abstract}

\section{ARTICLE HISTORY}

Received 28 July 2016

Accepted 5 March 2017

\section{KEYWORDS}

Adjuncts to exercise; bicycle exercise; dynamic hyperinflation; maximum exercise capacity; NIMV; patient-ventilator interaction

\section{Introduction}

Although exercise capacity may be limited in individuals with chronic obstructive pulmonary disease (COPD) $(1,2)$, studies have shown that pulmonary rehabilitation can improve exercise performance in such individuals (3-5). There is evidence that high-intensity exercise training ( $80 \%$ of maximum) may be more effective than low-intensity exercise training $(50 \%$ of maximum) (6,7). Individuals with COPD may, however, be unable to attain the high-intensity training that is required to enable them to obtain maximum benefits from pulmonary rehabilitation $(4,8-11)$.

Short-term physiological effects of non-invasive mechanical ventilation (NIMV) in individuals with COPD during exercise includes: reduced breathlessness $(10,12,13)$, improved ventilatory capacity $(10,14,15)$, prevention of exercise-induced hypoxemia $(12,16)$, and improved exercise endurance $(12,13,17)$. Nonetheless, information regarding the effect of NIMV on maximum exercise workload (WLmax) is limited. Moga et al. (18) reported a decrease in WLmax with the application of Bi-level positive airway pressure (BiPAP) during exercise, and concluded that the BiPAP's single limb tubing for inspiration and expiration resulted in carbon dioxide $\left(\mathrm{CO}_{2}\right)$ rebreathing and contributed to the reduction in WLmax. The occurrence of $\mathrm{CO}_{2}$ rebreathing with BiPAP has been reported in both laboratory $(19,20)$ and clinical $(19,21)$ studies. In contrast, standard intensive care ventilators with separate inspiratory and expiratory limb tubing do not pose a risk for $\mathrm{CO}_{2}$ rebreathing. We, therefore, anticipated that the use of such a ventilator during exercise would eliminate $\mathrm{CO}_{2}$ rebreathing and increase WLmax.

There is evidence that different levels of pressure support can affect comfort in patients being weaned off mechanical ventilation (22). Most studies investigating the acute effects of pressure support ventilation (PSV) during exercise have either used fixed levels of support (commonly $\left.\sim 10 \mathrm{~cm} \mathrm{H}_{2} \mathrm{O}\right)(10,17,18,23$ ) or levels tailored to the individual's comfort $(13,14,24,25)$. Whether the use of a fixed versus an individually titrated level of PSV has a differential effect on WLmax remains unknown.

The purpose of this study was to evaluate the effect of both $10 \mathrm{~cm} \mathrm{H}_{2} \mathrm{O}$ of PSV and a fixed level of PSV established by titration of PSV to patient's comfort at rest during a symptomlimited incremental bicycle test, compared to unassisted exercise, on WLmax, breathing pattern, metabolic parameters, end-expiratory lung volume (EELV), and exercise-limiting symptoms in individuals with COPD.

CONTACT Jadranka Spahija @ jadranka.spahija@mcgill.ca $@$ Research Center, Hôpital du Sacré-Coeur de Montréal, Axe de Recherche en Maladies Chroniques, 5400 Boul. Gouin Ouest, Montréal, Quebec H4J 1C5, Canada.

Color versions of one or more of the figures in the article can be found online at www.tandfonline.com/icop.

(c) 2017 Taylor \& Francis Group, LLC 


\section{Methods}

\section{Study participants}

Clinically stable individuals aged 55-75 years, with moderate to very severe COPD (Forced expiratory volume in one second $\left[\mathrm{FEV}_{1}\right]<80 \%$ predicted and $\mathrm{FEV}_{1} /$ forced vital capacity $[\mathrm{FVC}]<70 \%)(26)$ were recruited into the study. Clinical stability was defined as no exacerbation, no respiratory symptoms and unchanged medications for four weeks prior to study (18). Exclusion criteria were: use of supplemental oxygen; neurological, orthopaedic, cardiovascular, and cognitive conditions that could limit exercise performance. Participants were asked to refrain from smoking on test days, and from eating 3 hours prior to testing. Ethics approvals were obtained from Hôpital du Sacré-Coeur de Montréal (CER 2012-762) and the Center for Interdisciplinary Research in Rehabilitation in Montreal (CRIR740-0512) review boards.

\section{Procedures}

A cross-over design involving 3 visits was used. Visit 1 involved anthropometric measurements, pulmonary function testing, and a resting 12-lead electrocardiogram. Participants performed a symptom-limited incremental bicycle exercise at each visit. This involved subjects breathing at rest for six minutes, followed by one minute of unloaded pedalling (Lode, Groningen, the Netherlands), after which exercise work rate was increased by five watts every minute until a symptom-limited end-point. The pedalling rate was $60 \pm 8 \mathrm{rpm}$. Inspiratory capacity (IC) maneuvers were performed every minute during resting breathing and exercise, and at end-exercise. Participants identified the locus of their symptom limitation at end-exercise.

The three exercise tests, separated by at least 48 hours, were performed in a randomized order with no ventilator $(\mathrm{NV})$, pressure support ventilation of $10 \mathrm{~cm} \mathrm{H}_{2} \mathrm{O}$, and pressure support ventilation titrated to comfort at rest (PSVt) delivered using a Maquet SERVO-i ventilator. Before the start of the exercise test with PSVt, titration of PSV was performed with the subject seated comfortably on the bicycle and connected to the breathing circuit with a Maquet SERVO-i ventilator in the PSV mode with support level set to $10 \mathrm{~cm} \mathrm{H}_{2} \mathrm{O}$. After 3 mins of familiarization with $10 \mathrm{~cm} \mathrm{H}_{2} \mathrm{O}$, subjects were asked if they needed the PSV level to be increased, decreased, or left unchanged. Subsequently, titration was performed every 2-3 minutes by units of $\pm 2 \mathrm{~cm}$ $\mathrm{H}_{2} \mathrm{O}$ until $\pm 5 \mathrm{~cm} \mathrm{H}_{2} \mathrm{O}$ above or below (i.e. $5 \mathrm{~cm} \mathrm{H}_{2} \mathrm{O}$ or $15 \mathrm{~cm}$ $\mathrm{H}_{2} \mathrm{O}$ ) beyond which titration was done by units of $\pm 1 \mathrm{~cm} \mathrm{H}_{2} \mathrm{O}$ until the patient indicated the optimal level of comfort. Positive end-expiratory pressure (PEEP) was set to $4 \mathrm{~cm} \mathrm{H}_{2} \mathrm{O}$, rate of rise at 0.2 seconds and cycling at $50 \%$ of peak flow.

\section{Instrumentation and measurements}

WLmax was defined as the highest workload reached and maintained for at least 30 seconds. During resting breathing and exercise, subjects wore nose clips and breathed through a mouthpiece connected to a respiratory circuit consisting of a pneumotachograph (Model 4813; Hans Rudolph, Kansas City, MO, USA), pulmonary gas exchange analyzer (COSMED K4b2, Rome, Italy) and two-way non-rebreathing valve (Hans Rudolph
USA). For the visits where exercise was performed with ventilatory support, a Maquet SERVO-i ventilator (PSV mode) was added to the circuit along with a Hans Rudolph threeway sliding-type valve (manual direction control valve 2870 series) on the inspiratory limb. Airflow was measured using the pneumotachograph and a differential pressure transducer (TSD160A-Differential Pressure, $2.5 \mathrm{~cm} \mathrm{H20,} \mathrm{DA100C,} \mathrm{Biopac}$ Systems, Santa Barbara, CA, USA). Volume was obtained by digital integration of flow. Mouth pressure (Pmo) was recorded from a side port on the mouthpiece and connected to a separate pressure transducer (TSD160E-Differential Pressure, $350 \mathrm{~cm}$ H20, DA100C, Systems, Santa Barbara, CA, USA). In all trials, the flow and pressure signals were acquired online on a personal computer at a sampling rate of $1000 \mathrm{~Hz}$ using a 16-bit A/D converter (MP 100A-CE, Biopac Systems, Santa Barbara, CA, USA), and stored for offline analysis. Oxygen consumption $\left(\mathrm{VO}_{2}\right)$ and carbon dioxide production $\left(\mathrm{VCO}_{2}\right)$, heart rate, and oxygen saturation were measured with a COSMED system (COSMED K4b2, Rome, Italy). Electrocardiography (ECG) was monitored online during the test. Dyspnea and leg fatigue were assessed every minute using the modified 10-point Borg scale (27).

Breath-by-breath timing parameters of the breathing pattern, including respiratory rate (RR); inspiratory, expiratory, and total breath durations were determined from the flow signal using AcqKnowledge version 4.1. Mean and peak inspiratory and expiratory Pmo were obtained from the pressure signal. The time delay and associated pressure required to trigger the ventilator (Ptrig) were measured from the point where the Pmo signal declined below $4 \mathrm{~cm} \mathrm{H}_{2} \mathrm{O}$ (set PEEP) and the subsequent onset of inspiratory flow. End-expiratory lung volume (EELV) was obtained by subtracting the IC from measures of total lung capacity previously obtained during pulmonary function testing. Breath-by-breath data were averaged from the last two minutes of resting breathing, and each minute of exercise in every subject studied. Group means were calculated using these means.

\section{Statistical analysis}

Outcome measures were compared between conditions of NV, PSV10, and PSVt at rest and peak exercise using one-way repeated measures analysis of variance (SPSS v.19). Post-hoc contrasts were performed using the protected Fisher's least significant difference analysis. The significance level was set at $\alpha=$ 0.05 . Results are reported as means \pm standard deviation (SD).

\section{Results}

\section{Patient characteristics}

Eleven participants with moderate to severe COPD were recruited into the study. Patient characteristics are summarized in Table 1.

\section{Titration and ventilator pressures}

There was marked inter-individual variability in the PSV levels chosen by participants when PSV was titrated to comfort at rest (Fig. 1). The average PSVt level was $8.2 \pm 4.5 \mathrm{~cm} \mathrm{H}_{2} \mathrm{O}$. 
Table 1. Characteristics of the 11 patients with COPD.

\begin{tabular}{|c|c|}
\hline Variable & Mean \pm SD \\
\hline \multicolumn{2}{|l|}{ Anthropometric data } \\
\hline Age, years & $64 \pm 7$ \\
\hline Height, m & $1.67 \pm 0.06$ \\
\hline Weight, kg & $77.5 \pm 27.0$ \\
\hline $\mathrm{BMI}, \mathrm{kg} / \mathrm{m}^{2}$ & $27.5 \pm 8.1$ \\
\hline \multicolumn{2}{|l|}{ Baseline exercise capacity } \\
\hline 6MWD, m & $465 \pm 100$ \\
\hline \multicolumn{2}{|l|}{ Pulmonary function } \\
\hline $\mathrm{FEV}_{1}, \mathrm{~L}(\%$ pred $)$ & $1.4 \pm 0.3(49 \pm 16)$ \\
\hline $\mathrm{FEV}_{1} / \mathrm{FVC}, \%$ & $43 \pm 9$ \\
\hline FRC, L (\% pred) & $4.6 \pm 1.3(144 \pm 37)$ \\
\hline TLC, L (\% pred) & $7.1 \pm 1.4(120 \pm 21)$ \\
\hline RV, L (\% pred) & $3.8 \pm 1.3(165 \pm 47)$ \\
\hline $\mathrm{RV} / \mathrm{TLC}, \%$ & $52 \pm 9$ \\
\hline PImax, $\mathrm{cm} \mathrm{H}_{2} \mathrm{O}$ (\% pred) & $76.0 \pm 36.4(74 \pm 30)$ \\
\hline PEmax, $\mathrm{cm} \mathrm{H}_{2} \mathrm{O}$ (\% pred) & $94.6 \pm 45.6(51 \pm 20)$ \\
\hline $\mathrm{DLCO}, \mathrm{ml} / \mathrm{mmHg} / \mathrm{min}$ (\% pred) & $12.7 \pm 3.9(51 \pm 14)$ \\
\hline $\mathrm{SaO}_{2}, \%$ & $96 \pm 2$ \\
\hline
\end{tabular}

Values are means \pm SD. Definitions of abbreviations: $\mathrm{BMI}=$ body mass index; $6 \mathrm{MWD}$ $=6$-minute walk distance; $\mathrm{FEV}_{1}=$ forced expiratory volume in 1 st second; $F V C=$ forced vital capacity; $F R C=$ functional residual capacity; $R V=$ residual volume; TLC $=$ total lung capacity; PImax $=$ maximum inspiratory pressure; $P E m a x=$ maximum expiratory pressure; $\mathrm{DLCO}=$ diffusion capacity of the lung for carbon monoxide; $\mathrm{SaO}_{2}=$ arterial oxygen saturation.

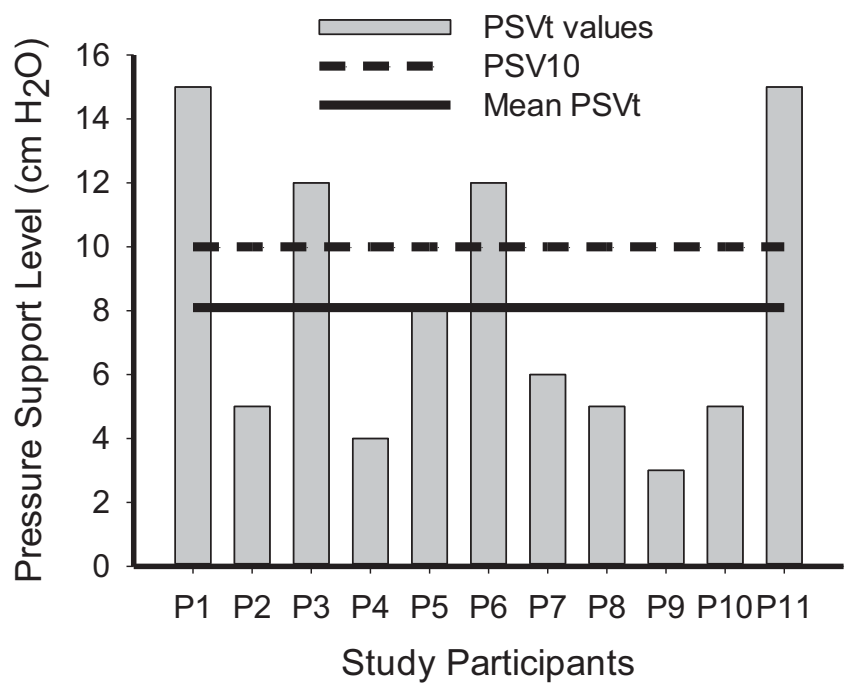

Figure 1. Pressure support levels titrated to patient comfort (PSVt). Each bar represents a single participant and the height shows the level of pressure support chosen by the participant during PSVt. PSV10 = pressure support ventilation with assist of $10 \mathrm{~cm} \mathrm{H}_{2} \mathrm{O}$; PSVt = pressure support ventilation titrated to comfort; horizontal bars are the mean WLmax achieved.

\section{Maximum exercise workload}

There was no difference in the group averages for WLmax. Figure 2 shows the group averages (A) and the individual levels of WLmax (B) with each ventilator strategy. Only 3 patients systematically increased their WLmax with both PSV10 and PSVt.

\section{Breathing pattern, lung volumes, and metabolic parameters}

Compared to $\mathrm{NV}$, tidal volume $\left(\mathrm{V}_{\mathrm{T}}\right)$ was significantly higher with PSV10 during resting breathing ( $p \leq 0.001$ ), and there was a similar tendency with PSVt $(p=0.053)$. Also at rest, inspiratory duration was shorter $(p=0.009 ; p=0.004)$ and minute ventilation $\left(V_{\mathrm{E}}\right)$ higher $(p \leq 0.001 ; p=0.027)$ with both PSV10 and
PSVt, respectively. These effects were not observed at peak exercise (Fig. 3). Compared to NV, expiratory duration was longer with both PSV10 $(p=0.004)$ and PSVt $(p=0.043)$ at peak exercise, whereas RR was reduced only with PSV10 ( $p=0.007)$. Similarly, peak inspiratory flow was higher $(p<0.001)$ at rest with PSV10 (1.37 \pm 0.13$)$ and PSVt $(1.21 \pm 0.13)$ compared to NV $(0.77 \pm 0.13)$, whereas at peak exercise, there was no difference $(\mathrm{NV}=2.28 \pm 0.71, \mathrm{PSV} 10=2.23 \pm 0.44, \mathrm{PSVt}=2.25 \pm 0.58)$

Exercise increased EELV in all ventilatory conditions (Fig. 4). The EELV during resting breathing was $411 \pm 354 \mathrm{ml}$ higher with PSV10 ( $p=0.003)$ and $545 \pm 426 \mathrm{ml}$ higher with PSVt $(p=0.002)$ compared to NV. In contrast, at peak exercise, the EELV was higher $(299 \pm 222 \mathrm{ml})$ only with PSVt (Fig. 4$)$.

Compared to NV, end-tidal carbon dioxide was lower with PSV10 $(p \leq 0.001)$ and PSVt $(p=0.005)$ during resting breathing (Fig. 5), but this effect was not evident at peak exercise. The $\mathrm{VO}_{2}$ and $\mathrm{VCO}_{2}$ were similar with and without ventilatory assist at rest and peak exercise (Fig. 5).

\section{Other outcomes}

We found no difference in dyspnea ratings at rest, at 25 and 50\% of WLmax, and at peak exercise. There was also no difference in leg effort, heart rate, and arterial oxygen saturation between the three exercise conditions both at rest and peak exercise. There was no evidence of significant desaturation during the exercise (defined as a decrease in $\mathrm{SpO}_{2}$ to a level $<89 \%$ and sustained for a minimum of one minute during exercise (28)).

\section{Ventilator pressure, triggering, and cycling during exercise}

The mean inspiratory Pmo during ventilator-assisted exercise decreased progressively as exercise intensity increased to peak, despite the peak Pmo remaining unchanged (Fig. 6a and b). Mean expiratory Pmo increased progressively with PSV10 and PSVt during exercise (Fig. 6c), whereas it was negligible with NV.

Compared to resting breathing, the delay in ventilator triggering at peak exercise was reduced by 41 and $27 \mathrm{msec}$ with PSV10 and PSVt, respectively. In contrast, Ptrig increased progressively with increased exercise intensity (Fig. 6d); the increase was smaller with PSV10 (192\%) compared to PSVt (357\%). The tracings of flow, volume, and Pmo signals at rest, 50\% exercise, $70 \%$ exercise, and peak exercise presented in Figure 7 show a loss of the positive square wave pattern of PSV and an increase in expiratory Pmo with progression in exercise intensity (Panel A-PSV10 and panel B-PSVt).

\section{Discussion}

In the current study, compared to no assist, PSV delivered noninvasively during exercise did not improve WLmax, both when PSV was set to $10 \mathrm{~cm} \mathrm{H}_{2} \mathrm{O}$ level of assist, and a fixed level established by titration of PSV to patient's comfort at rest. Although most individuals reported being more comfortable when PSVt was set lower than $10 \mathrm{~cm} \mathrm{H} \mathrm{H}_{2} \mathrm{O}$, the physiological effects of both PSV10 and PSVt (increased $\mathrm{V}_{\mathrm{T}}, \mathrm{V}_{\mathrm{E}}$, and lower Ti) were not sustained at higher exercise intensities. In fact, mean inspiratory Pmo decreased progressively, whereas Ptrig and mean expiratory Pmo were increased at peak exercise, suggesting that the 

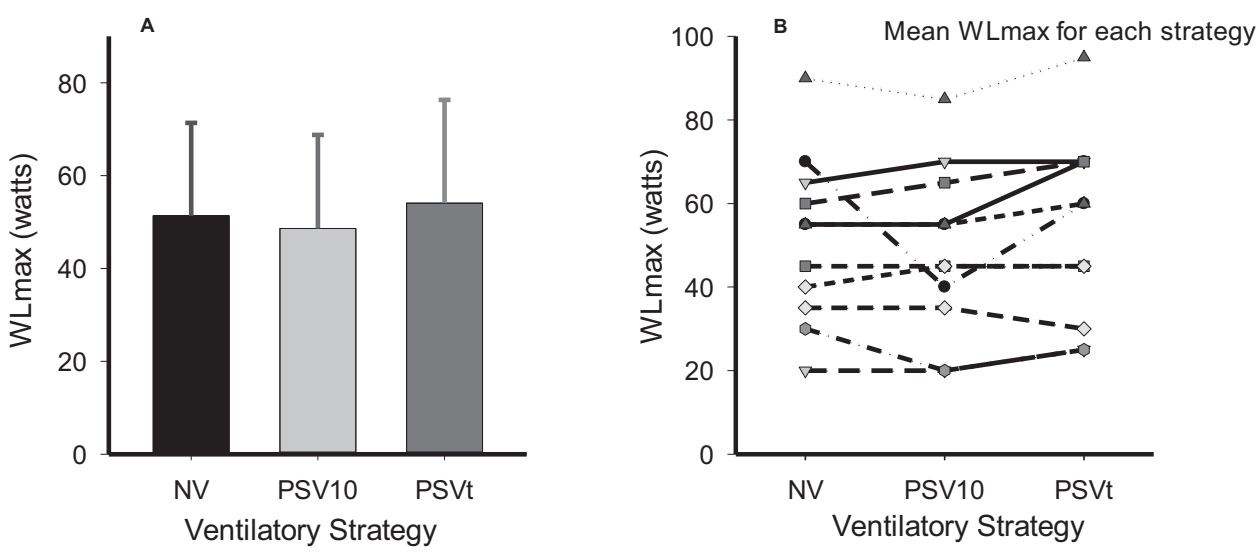

Figure 2. Maximum workload reached during the three experimental conditions. Group mean values (SD) of WLmax reached during symptom-limited incremental bicycle exercise with NS (black bar), with PSV10 (light grey bar) and with PSvt (dark grey bar) are $51 \pm 19$ W, $48 \pm 20 \mathrm{~W} 53 \pm 21$ W, respectively (panel A). Individual values are shown in panel B; WLmax was higher in 3 participants (range: 5 w), unchanged in 5 participants and lower in 3 others (range: $5-30$ w), whereas with PSVt it was higher in 7 participants (range: 5-15 w), lower in 3 (range: 5-10 w), and unchanged in 1. The mean WLmax achieved was 51.36 $\pm 20.01,48.64 \pm 20.14$ and $54.09 \pm 22.23 \mathrm{~W}$ with NV, PSV10 and PSVt, respectively. WLmax = maximum workload achieved; $\mathrm{NV}=$ no ventilator; $\mathrm{PSV} 10=$ pressure support ventilation $10 \mathrm{~cm} \mathrm{H}_{2} \mathrm{O}$ of assist; PSVt $=$ pressure support ventilation titrated to comfort; horizontal bars are the mean WLmax achieved.

ventilator was unable to keep up with the increased ventilatory demand at higher workloads.

Although several studies previously looked at the immediate physiological effects of NIMV during exercise in people with $\operatorname{COPD}(10,13,14,17,18,23-25)$, only one study evaluated the effect on WLmax (18). That study found a decrease in WLmax with the application of BiPAP during exercise, and $\mathrm{CO}_{2}$ rebreathing was identified as a likely contributing factor (18).
Studies which evaluated the effect of bi-level positive pressure ventilation on exercise endurance reported a decreased walking distance during submaximal treadmill exercise (15) or no difference in shuttle walk test endurance time (23). The presence of $\mathrm{CO}_{2}$ rebreathing (15) or an insufficient pre-set pressure level of $10 \mathrm{~cm} \mathrm{H}_{2} \mathrm{O}$ (23) were proposed as factors contributing to the results obtained in those studies. In contrast, studies that used fixed $(17)$ and titrated $(13,14,25)$ levels of PSV during constant
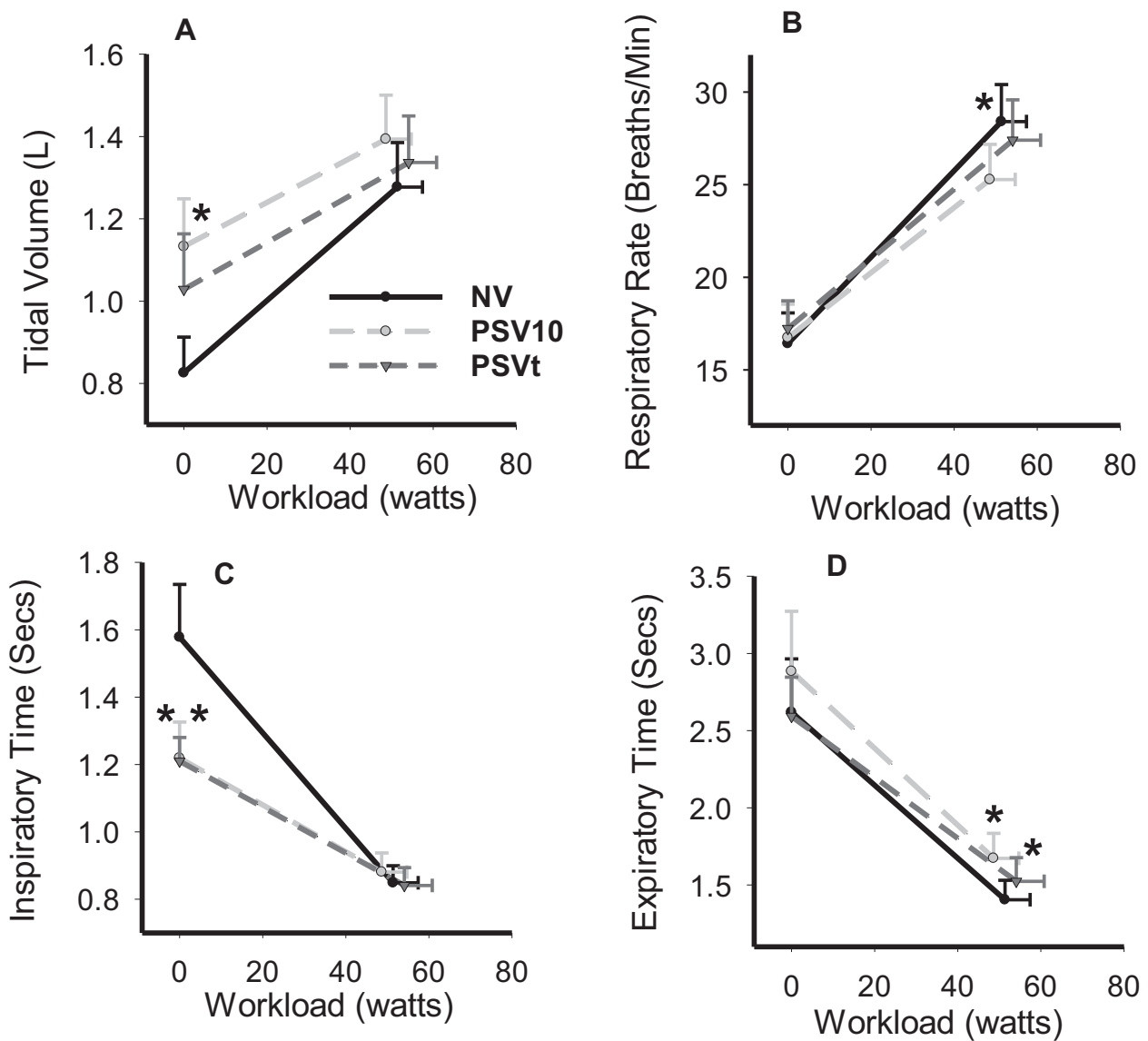

Figure 3. Tidal volume (A), respiratory rate (B), inspiratory time (C) and expiratory time (D) at rest and peak exercise. Plots are average values $\pm S E$ obtained in the 11 participants. PSV10 $=$ pressure support ventilation $10 \mathrm{~cm} \mathrm{H}_{2} \mathrm{O}$ of assist; PSVt $=$ pressure support ventilation titrated to comfort. For post-hoc contrasts: ${ }^{*} p<0.05$, relative to no ventilator. 


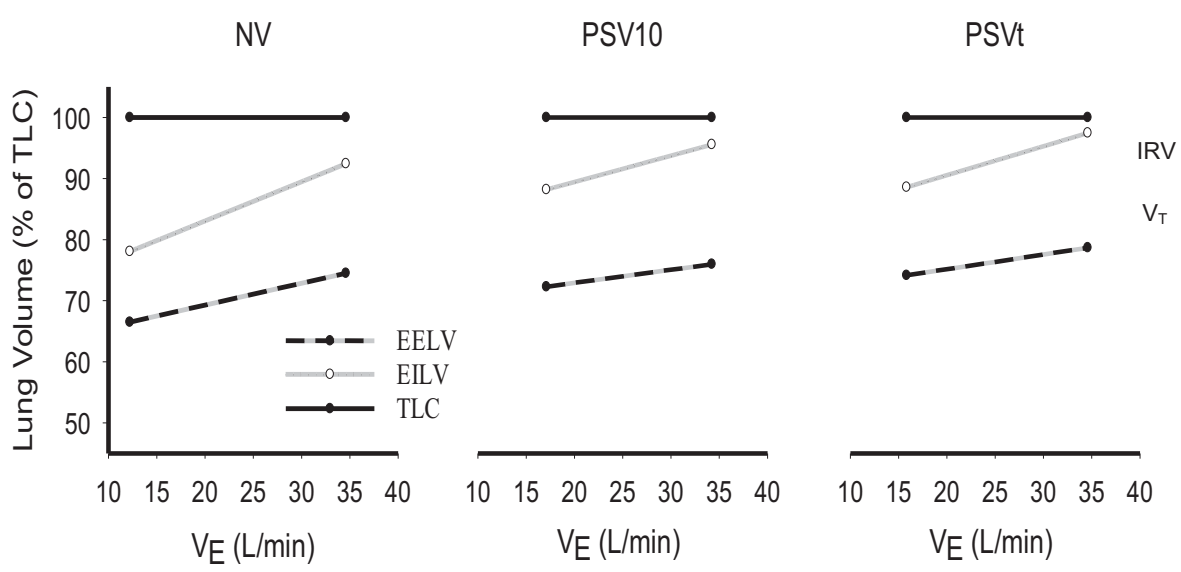

Figure 4. Plots of EELV (dark and grey line), EILV (grey line) and TLC (dark line) at rest and peak exercise for NV, PSV10 and PSVt. Plots are average values in the 11 participants. $\mathrm{EELV}=$ end-expiratory lung volume; $\mathrm{EILV}=$ end inspiratory lung volume; $\mathrm{TLC}=$ total lung capacity; $I R V=$ inspiratory reserve volume, $\mathrm{V}_{\mathrm{T}}=$ tidal volume; $\mathrm{NV}=$ no ventilator; PSV10 $=$ pressure support ventilation with assist of $10 \mathrm{~cm} \mathrm{H}_{2} \mathrm{O} ; \mathrm{PSVt}=$ pressure support ventilation titrated to comfort. For post-hoc contrasts: ${ }^{*} p<0.05$ : PSV10 and PSVt relative to $\mathrm{NV}^{\dagger} p<0.05$ : peak relative to rest.

workload exercise reported increases in exercise endurance $(13,14,17,25)$. We did not observe an increase in WLmax when PSV was applied during incremental bicycle exercise. Although exercise endurance may be a more sensitive measure for detecting a change in response to an intervention than is WLmax (29), we believe that poor ventilator responsiveness at higher exercise workloads and greater dynamic hyperinflation in our subjects were factors that likely contributed to our findings.

A higher EELV at rest with PSV indicates that our subjects hyperinflated with the ventilator before the commencement of exercise as was also reported in a previous study (18). We used a PEEP of $4 \mathrm{~cm} \mathrm{H}_{2} \mathrm{O}$ in the current study because a moderate level of PEEP has been shown to reduce the muscle inspiratory effort without any further increase in the lung volume during assisted ventilation in patients with airflow obstruction (30) and the same level was used in a previous study (18). It is known that the application of an external PEEP greater than the intrinsic PEEP (PEEPi) in flow-limited patients will reduce the driving pressure for expiratory flow and result in a higher $\operatorname{EELV}(31,32)$. Although we did not measure PEEPi, it is possible that application of $4 \mathrm{~cm} \mathrm{H}_{2} \mathrm{O}$ of PEEP could have exceeded the critical value of PEEPi resulting in the increased EELV at rest. Similar to previous studies, we observed an increased EELV with exercise whether or not mechanical ventilation was used $(14,18)$. In individuals with $C O P D, V_{E}$, which increases progressively with increased workload, is achieved predominantly by an increased RR which in turn results in less time available for expiration, and predisposes individuals to dynamic hyperinflation (33). At peak exercise, EELV remained higher with PSVt and not PSV10 which may be explained by higher RR with PSVt compared to PSV10.

Higher $\mathrm{V}_{\mathrm{T}}, \mathrm{V}_{\mathrm{E}}$, and inspiratory flow, observed in the current study with PSV during resting breathing is consistent with breathing pattern changes previously reported both during conditions of rest (34) and sub-maximum exercise (10). In our study, these effects were not sustained at peak exercise. As observed in Fig. 4, end-inspiratory lung volume (EILV) was already close TLC with PSV at rest so that no appreciable increase could be afforded by the ventilator as exercise progressed to peak.

In the current study, the loss of the positive square wave pattern of the PSV gives evidence to the assertion of a progressive increase in respiratory (flow) demand that could not be matched by the ventilator (flow asynchrony) (35). Flow asynchrony can be detected as a loss of the positive square wave pattern or the presence of concavity in the pressure-time waveform $(36,37)$. The Pmo tracing from one of our study participants, presented in Figure 7, shows loss of the positive square wave pattern between $70 \%$ and peak exercise workloads (seen in all our participants at workloads $>70 \%$ ). Similar Pmo tracings were
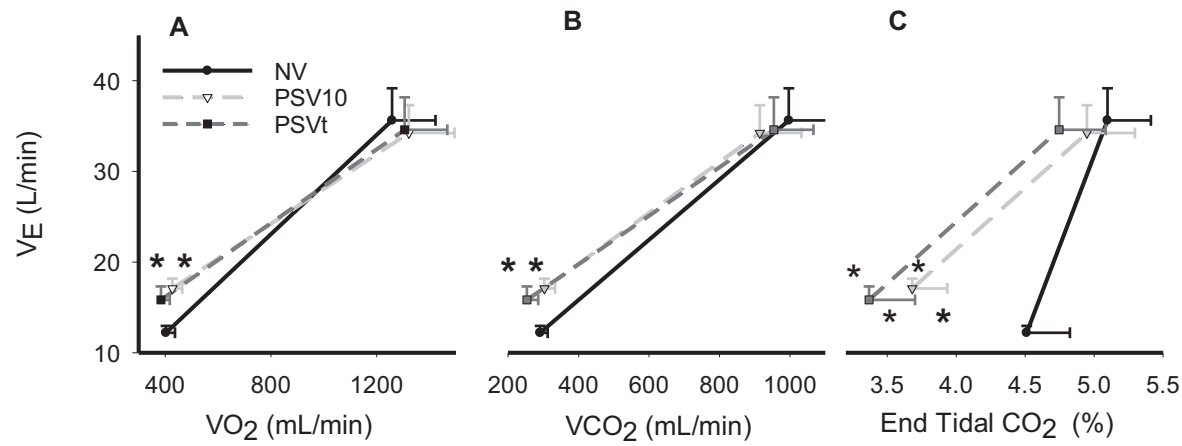

Figure 5. Plot of oxygen uptake (A), carbon dioxide output (B), and end-tidal $\mathrm{CO} 2(\mathrm{C})$ vs minute ventilation at rest and peak exercise. Plots are average values \pm SE obtained in the 11 participants. $\mathrm{NV}=$ no ventilator; $\mathrm{PSV10}=$ pressure support ventilation with assist of $10 \mathrm{~cm} \mathrm{H}_{2} \mathrm{O} ; \mathrm{PSVt}=$ pressure support ventilation titrated to comfort. For post-hoc contrasts: ${ }^{*} p<0.05$, relative to without NV. 

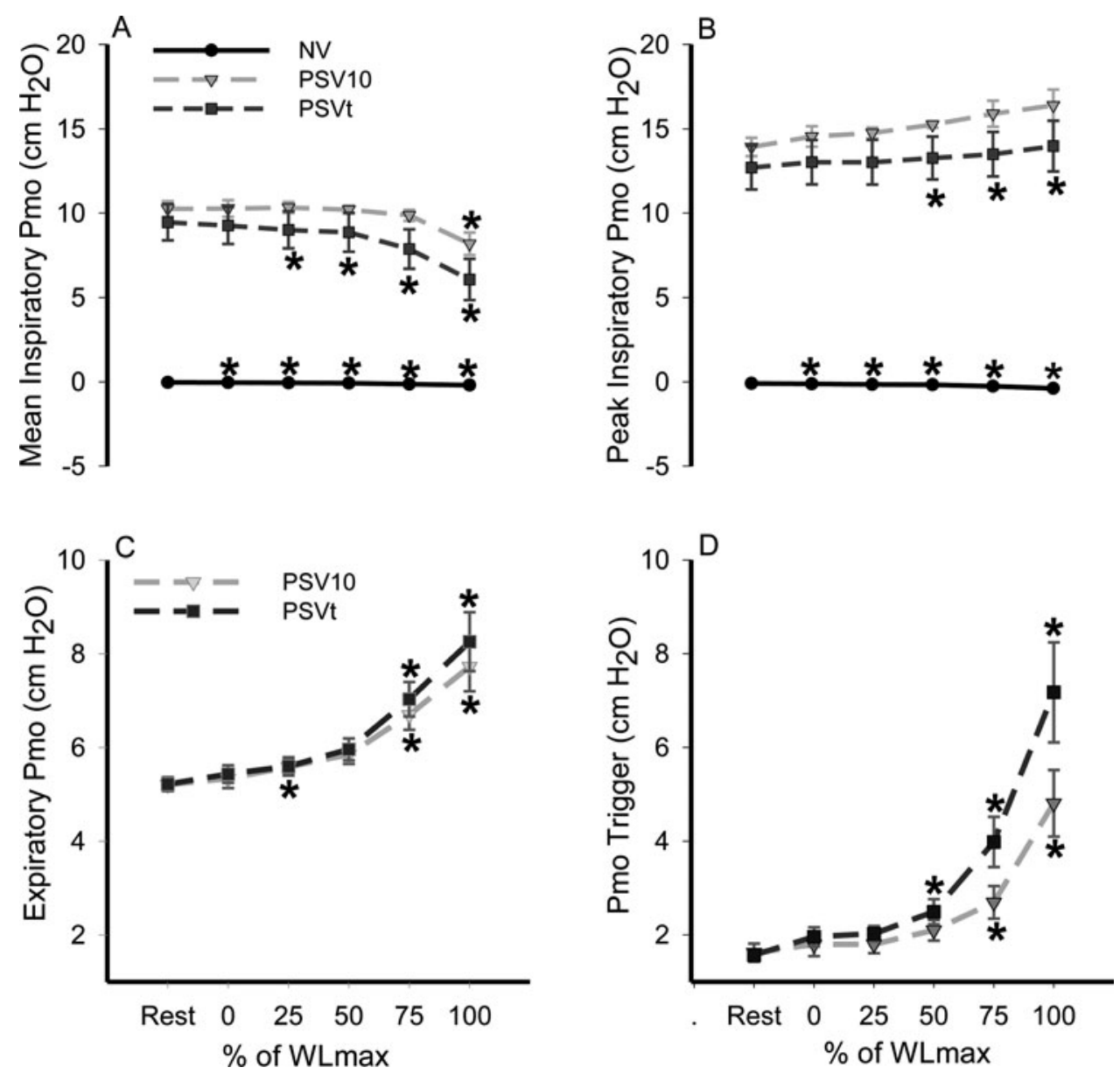

Figure 6. Mouth and trigger pressures at rest and during exercise. (A) Mean inspiratory and (B) peak inspiratory mouth pressures with NV, PSV10 and PSVt. The peak and mean inspiratory Pmo became progressively more negative ( $p \leq 0.002$ and $p \leq 0.002$ respectively) with no ventilator as exercise intensity increased. While, during ventilator assisted exercise, mean inspiratory Pmo decreased as exercise intensity increased (PSV10: $p \leq 0.02$ and PSVt: $p \leq 0.001$ ) whereas peak inspiratory Pmo was sustained. (C) Mean expiratory mouth pressures with PSV10 and PSVt. The mean (SD) increase was 2.5 (0.5) H2O and $3.0(0.6) \mathrm{cm} \mathrm{H2O} \mathrm{with} \mathrm{PSV10} \mathrm{and} \mathrm{PSVt,} \mathrm{respectively} \mathrm{(PSV10:} p \leq 0.000$ and PSVt: $p \leq 0.000$ ). (D) Ventilator Inspiratory Trigger Pressure below the level of set PEEP of $4 \mathrm{~cm} \mathrm{H}_{2} \mathrm{O}$. The ventilator trigger pressure (Ptrig) increased from $1.6 \mathrm{~cm} \mathrm{H}_{2} \mathrm{O}$ during resting breathing to $4.8 \mathrm{~cm} \mathrm{H}_{2} \mathrm{O}$ at peak exercise with PSV10 $(p \leq 0.001)$ and from 1.6 to $7.2 \mathrm{~cm} \mathrm{H}_{2} \mathrm{O}$ with PSVt $(p \leq 0.000)$. Plots are average values \pm SE obtained in the 11 participants. $\mathrm{PSV} 10=$ pressure support ventilation $10 \mathrm{~cm} \mathrm{H}_{2} \mathrm{O}$ of assist; $\mathrm{PSVt}=$ pressure support ventilation titrated to comfort; WLmax: maximum exercise workload; $\mathrm{Pmo}=$ mouth pressure. For post-hoc contrasts: ${ }^{*} p<0.05$, relative to resting breathing.

observed by Dolmage et al. (38) at 60-70\% of maximum exercise during proportional assist ventilation assisted exercise. Since our assist level was fixed during the exercise, it is possible that loss of the Pmo positive square wave was due to an increased patient effort which increased flow demand beyond what the ventilator was able to furnish. (36). The progressive decrease in mean but not peak inspiratory Pmo could also be interpreted as further evidence of an increased flow demand during PSV assisted exercise. However, one should be cautious making such an interpretation considering that a component of the Pmo, which was the more negative Ptrig, likely also contributed to the decrease in the mean Pmo.

Studies which used the PSV during constant workload bicycle exercise at $75 \%(17)$ and $80 \%(13,14)$ of maximum, as well as during submaximal treadmill exercise (25) reported increases in exercise endurance. Van't Hul et al. (17) reported that the increase in endurance time was only consistent in fifteen of their forty-five participants. In light of our findings, perhaps an inability of the ventilator to sustain the ventilatory demand at $75 \%$ of max also contributed to results obtained in that study. Earlier studies have suggested that when the ventilator is unable to generate sufficient inspiratory flow rates to deliver the preset level of pressure support throughout exercise, the resistance of the circuit may worsen dyspnea and impair exercise performance (23).

The flow asynchrony at higher workloads reported in this study should be considered in light of the capacity and setting of the ventilator. The Maquet SERVO-i has a maximum inspiratory flow rate of $3.3 \mathrm{l} / \mathrm{s}$ (39) notwithstanding the resistance provided by the respiratory circuit. Flow rate can be adjusted using the inspiratory rise time (36) (range of $0.0-0.4$ seconds on the Maquet SERVO-I (39)). We used a rise time of 0.2 seconds since very short rise time (higher peak flow) is known to be associated with discomfort (40). Titrating the rise time during exercise might have altered our results, but to the best of our knowledge, no study has ever titrated this parameter during exercise in patients with COPD and it was also not feasible in our protocol.

This study is the first to report that the pressure required by the patient to trigger PSV on the Servo-I ventilator increases with workloads $>75 \% \max$ (Fig. $6 \mathrm{~d}$ ). While this may suggest increased effort, there was a corresponding decrease in the trigger delay which likely resulted in unchanged overall triggering effort. Increased Ptrig may be attributed to decreased sensitivity of the valve (trigger asynchrony) (36) during high respiratory demand. Adjusting the trigger sensitivity might have improved 

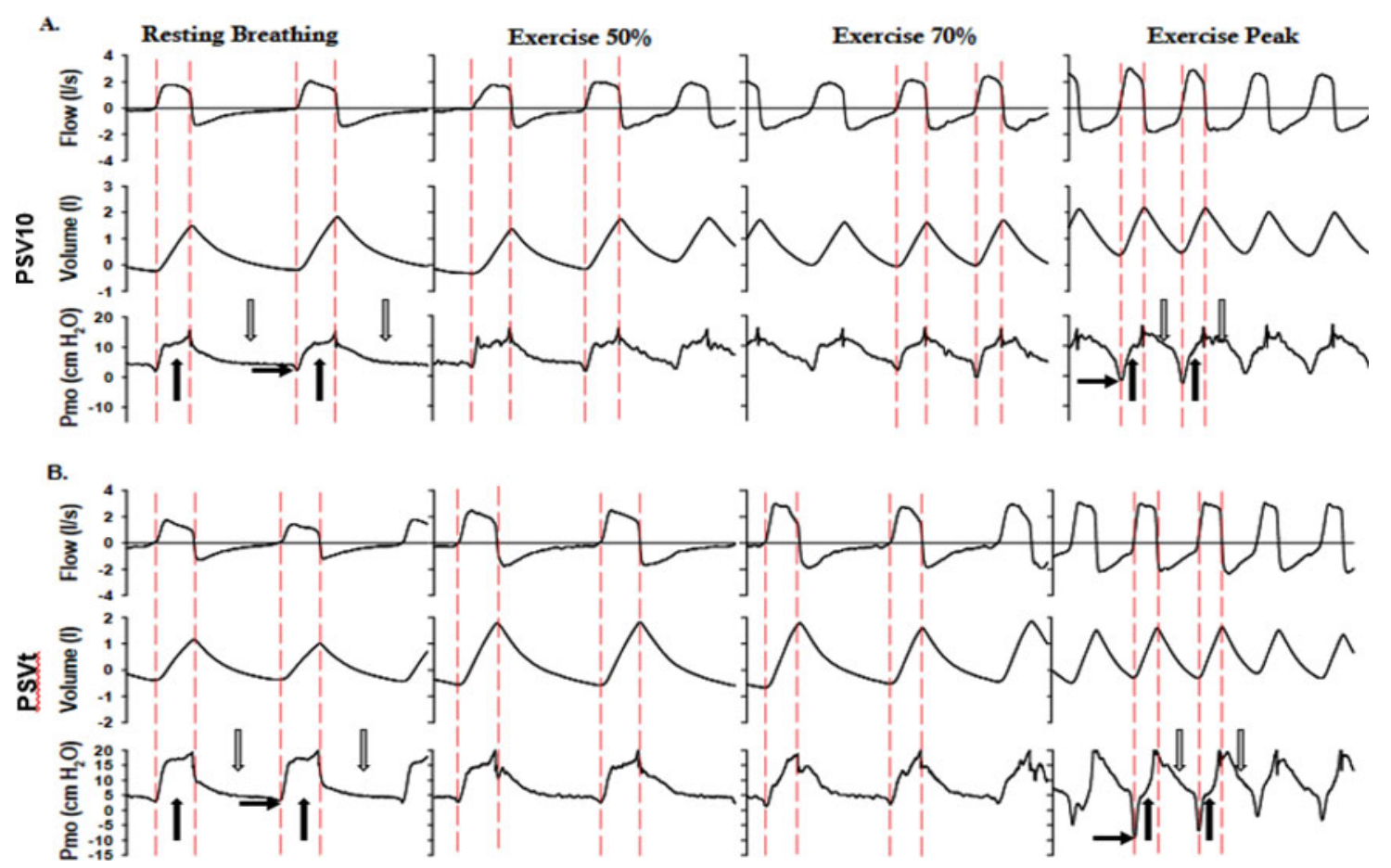

Figure 7. Flow, volume and mouth pressure signal at resting breathing, 50\% exercise, $70 \%$ exercise and at peak exercise in Participant 11 during PSV10 (panel A) and higher titrated pressure (PSVt) of $15 \mathrm{~cm} \mathrm{H}_{2} \mathrm{O}$ (panel B). The mean inspiratory pressure decreased with the loss of the positive square wave pattern of pressure support ventilation (vertical dark arrow), the mean expiratory pressure increased (vertical grey arrow) and the patient generated more pressure to trigger the ventilator into inspiration (horizontal dark arrow), as exercise progressed from rest to peak. This alternation of wave pattern at peak exercise was seen at varying degrees in all are participants and was

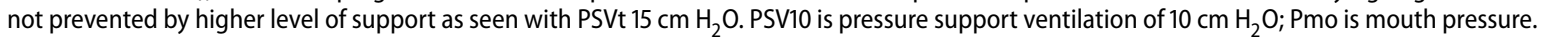

trigger asynchrony in PSV $(36,41)$ but the inspiratory trigger of the Maquet SERVO-i is nonadjustable in the NIMV mode. A ventilator with adjustable trigger sensitivity may thus present a different result.

Earlier studies have shown expiratory muscle recruitment during ventilator-assisted exercise with PSV (10), BiPAP (18) and continuous positive airway pressure (42) modes; however, our study was the first to show that this recruitment is more pronounced at workloads $>75 \%$ max during PSV-assisted exercise (Fig. 6c). This may be explained by an increasing dynamic hyperinflation which causes further flattening of the diaphragm necessitating expiratory muscle recruitment to assist diaphragmatic ascent during expiration in preparation for the next inspiration $(43,44)$.

There was no difference in dyspnea ratings at peak exercise both with PSV10 and PSVt. This can be attributed to changing respiratory dynamics with exercise, which is expected to be more pronounced in COPD because of dynamic hyperinflation and a progressive increase in the work of breathing. Trigger and flow asynchrony with PSV10 and PSVt may also be plausible explanation for the lack of difference in the dyspnea ratings. Earlier studies $(23,38)$ reported no difference in dyspnea ratings during ventilator-assisted exercise.

There are some limitations which should be considered when interpreting our findings. First, the pressure support level in the current study was fixed during exercise (both with PSV10 and PSVt) despite the changing dynamics of the respiratory system with incremental exercise. Titrating the support level during exercise might have yielded different findings, but this was not feasible in our study given that exercise workload was increased every minute and as we observed, it took more than a minute for patients to sense and respond to changes in comfort with changes in PSV level. Hussain et al. (14) titrated to comfort every two minutes during constant workload exercise performed at $80 \%$ of peak and found that exercise time was increased with PSV compared to no ventilator. Other studies which titrated support levels gave no details on when titration was performed, although all reported an increase in exercise endurance $(13,25)$. Familiarity with NIMV could potentially have affected performance when NIMV was used during exercise. Unfortunately, such information was not obtained in the study. Finally, this was a pilot study which was conducted in a small number of participants.

\section{Conclusion}

This study shows that both $10 \mathrm{~cm} \mathrm{H}_{2} \mathrm{O}$ of PSV and a fixed level of PSV titrated to comfort at rest, administered using a Maquet SERVO-i ventilator and delivered via a mouthpiece, do not improve WLmax in comparison to unassisted exercise. Our results suggest that PSV does not increase WLmax because of an inability of the Maquet SERVO-i ventilator to support an increased ventilatory demand at workloads close to peak exercise.

\section{Acknowledgments}

The authors would like to thank Happiness Anekwe for her technical support as well as the patients for their participation in the study. Jadranka Spahija Ph.D. is the guarantor of the content of this manuscript, including the data and analysis. 


\section{Declaration of interest}

The authors have no interests to declare.

\section{Authors' contribution}

D. Anekwe was responsible for coordinating the overall activities of the study including arranging for recruitment, scheduling of the tests, running of the study, as well as data collection and analysis and writing of manuscripts. J. Spahija contributed to the study conception, design, patient recruitment, supervision and assistance during data collection, interpretation of the results as well as proofreading and editing of all the documents and the final manuscript. M. de Marchie participated in the clinical supervision during the exercise tests, translation of all documents to French language, review of selected medical files and medical screening of all recruited participants. He also offered necessary feedback and advice before and during the study, as well as review of the manuscript.

\section{References}

1. Bernard S, LeBlanc P, Whittom F, Carrier G, Jobin J, Belleau R, et al. Peripheral muscle weakness in patients with chronic obstructive pulmonary disease. Am J Respir Crit Care Med 1998;158(2):629-634.

2. Killian KJ, Leblanc P, Martin DH, Summers E, Jones NL, Campbell EJ. Exercise capacity and ventilatory, circulatory, and symptom limitation in patients with chronic airflow limitation. Am Rev Respir Dis 1992;146(4):935-940.

3. British Thoracic Society Standards of Care Subcommittee on Pulmonary Rehabilitation. Pulmonary rehabilitation. Thorax 2001;56(11):827-834.

4. De Backer LA, Ides K, Daems D, Dieriks B, De Backer WA, Germonpre P. Pulmonary rehabilitation and non-invasive ventilation in COPD. Acta Clin Belg 2010;65(5):330-335.

5. Ries AL, Kaplan RM, Limberg TM, Prewitt LM. Effects of Pulmonary Rehabilitation on Physiologic and Psychosocial Outcomes in Patients with Chronic Obstructive Pulmonary Disease. Ann Intern Med 1995;122(11):823-832.

6. Casaburi R, Porszasz J, Burns MR, Carithers ER, Chang RS, Cooper CB. Physiologic benefits of exercise training in rehabilitation of patients with severe chronic obstructive pulmonary disease. Am J Respir Crit Care Med 1997;155(5):1541-1551.

7. Casaburi R, Patessio A, Ioli F, Zanaboni S, Donner CF, Wasserman K. Reductions in exercise lactic acidosis and ventilation as a result of exercise training in patients with obstructive lung disease. Am Rev Respir Dis 1991;143(1):9-18.

8. Ambrosino N, Strambi S. New strategies to improve exercise tolerance in chronic obstructive pulmonary disease. Eur Respir J 2004;24(2):313-22.

9. Fuldl JP, Cotton MM. Performance enhancement in chronic obstructive pulmonary disease. Chron Respir Dis 2004;1(2):95-98.

10. Maltais F, Reissmann H, Gottfried SB. Pressure support reduces inspiratory effort and dyspnea during exercise in chronic airflow obstruction. Am J Respir Crit Care Med 1995;151(4):1027-1033.

11. Maltais F, LeBlanc P, Jobin J, Bérubé C, Bruneau J, Carrier L, et al. Intensity of training and physiologic adaptation in patients with chronic obstructive pulmonary disease. Am J Respir Crit Care Med 1997;155(2):555-561.

12. Dreher M, Storre JH, Windisch W. Noninvasive ventilation during walking in patients with severe COPD: a randomised cross-over trial. Eur Respir J 2007;29(5):930-936.

13. Bianchi L, Foglio K, Pagani M, Vitacca M, Rossi A, Ambrosino N. Effects of proportional assist ventilation on exercise tolerance in COPD patients with chronic hypercapnia. Eur Respir J 1998;11(2):422-427.

14. Hussain O, Collins EG, Adiguzel N, Langbein WE, Tobin MJ, Laghi F. Contrasting pressure-support ventilation and helium-oxygen during exercise in severe COPD. Respir Med 2011;105(3):494-505.

15. Highcock MP, Shneerson JM, Smith IE. Increased ventilation with NiIPPV does not necessarily improve exercise capacity in COPD. Eur Respir J 2003;22(1):100-105.
16. Hernandez P, Maltais F, Gursahaney A, Leblanc P, Gottfried SB. Proportional assist ventilation may improve exercise performance in severe chronic obstructive pulmonary disease. J Cardiopulm Rehabil 2001;21(3):135-142.

17. van 't Hul A, Gosselink R, Hollander P, Postmus P, Kwakkel G. Acute effects of inspiratory pressure support during exercise in patients with COPD. Eur Respir J 2004;23(1):34-40.

18. Moga AM, de Marchie M, Saey D, Spahija J. Bi-level Positive Airway Pressure (BiPAP) with standard exhalation valve does not improve maximum exercise capacity in patients with COPD. COPD 2015;12(1):46-54.

19. Lofaso F, Brochard L, Touchard D, Hang T, Harf M, Isabey D. Evaluation of Carbon Dioxide Rebreathing During Pressure Support Ventilation With Airway Management System (BiPAP) Devices. Chest 1995;108(3):772-778.

20. Lofaso F, Brochard L, Hang T, Lorino H, Harf A, Isabey D. Home versus intensive care pressure support devices. Experimental and clinical comparison. Am J Respir Crit Care Med 1996;153(5):1591-1599.

21. Ferguson GT, Gilmartin M. CO2 rebreathing during BiPAP ventilatory assistance. Am J Respir Crit Care Med 1995;151(4):1126-1135.

22. Vitacca M, Bianchi L, Zanotti E, Vianello A, Barbano L, Porta R, et al. Assessment of physiologic variables and subjective comfort under different levels of pressure support ventilation. Chest 2004;126(3):851859.

23. Menadue C, Alison JA, Piper AJ, Flunt D, Ellis ER. Non-invasive ventilation during arm exercise and ground walking in patients with chronic hypercapnic respiratory failure. Respirology 2009;14(2): 251-259.

24. Kyroussis D, Polkey M, Hamnegard C, Mills G, Green M, Moxham J. Respiratory muscle activity in patients with COPD walking to exhaustion with and without pressure support. Eur Respir J 2000;15(4):649655.

25. Keilty SE, Ponte J, Fleming TA, Moxham J. Effect of inspiratory pressure support on exercise tolerance and breathlessness in patients with severe stable chronic obstructive pulmonary disease. Thorax 1994;49(10):990-994.

26. Global Initiative for Chronic Obstructive Lung Disease (GOLD). Global Strategy for the Diagnosis, Management and Prevention of COPD 2011 [cited 2012 January 6th]. Available from: http://www.goldcopd.org/

27. Kendrick KR, Baxi SC, Smith RM. Usefulness of the modified 0-10 Borg scale in assessing the degree of dyspnea in patients with COPD and asthma. J Emerg Nurs 2000;26(3):216-222.

28. Garvey C, Tiep B, Carter R, Barnett M, Hart M, Casaburi R. Severe Exercise-Induced Hypoxemia. Respir Care 2012;57(7):1154-1160.

29. Borel B, Provencher S, Saey D, Maltais F. Responsiveness of various exercise-testing protocols to therapeutic interventions in COPD. Pulm Med 2013;2013.

30. Chiumello D, Polli F, Tallarini F, Chierichetti M, Motta G, Azzari S, et al. Effect of different cycling-off criteria and positive end-expiratory pressure during pressure support ventilation in patients with chronic obstructive pulmonary disease*. Crit Care Med 2007;35(11):25472552.

31. Tobin MJ, Lodato RF. PEEP, auto-PEEP, and waterfalls. Chest 1989;96(3):449-451.

32. Gay PC, Rodarte JR, Hubmayr RD. The effects of positive expiratory pressure on isovolume flow and dynamic hyperinflation in patients receiving mechanical ventilation. Am Rev Respir Dis 1989;139(3):621626.

33. O'Donnell DE, Revill SM, Webb KA. Dynamic hyperinflation and exercise intolerance in chronic obstructive pulmonary disease. Am J Respir Crit Care Med 2001;164(5):770-777.

34. Fauroux B, Isabey D, Desmarais G, Brochard L, Harf A, Lofaso F. Nonchemical influence of inspiratory pressure support on inspiratory activity in humans. J Appl Physiol 1998;85(6):2169-2175.

35. MacIntyre NR, McConnell R, Cheng K-CG, Sane A. Patient-ventilator flow dyssynchrony: flow-limited versus pressure-limited breaths. Crit Care Med 1997;25(10):1671-1677.

36. Nilsestuen JO, Hargett KD. Using ventilator graphics to identify patient-ventilator asynchrony. Respir Care 2005;50(2):202-234. 
37. Branson RD, Blakeman TC, Robinson BR. Asynchrony and dyspnea. Respir Care 2013;58(6):973-989.

38. Dolmage TE, Goldstein RS. Proportional assist ventilation and exercise tolerance in subjects with COPD. Chest 1997 1997/04//:948+.

39. Maquet GETINGE GROUP. Data Sheet VENTILATION SERVO-i ${ }^{\circledR}$ ADULT 2012 [cited 2012 11/16/2012]. Available from: http://www. maquet.com/content/Documents/DataSheet_MainProduct/Servoi_ DATA_6670107_R13_v6dot1_129395_EN_A-LL.pdf

40. Manning HL, Molinary EJ, Leiter JC. Effect of inspiratory flow rate on respiratory sensation and pattern of breathing. Am J Respir Crit Care Med 1995;151(3):751-757.
41. Richard JC, Carlucci A, Breton L, Langlais N, Jaber S, Maggiore S, et al Bench testing of pressure support ventilation with three different generations of ventilators. Intensive Care Med 2002;28(8):1049-1057.

42. Petrof BJ, Calderini E, Gottfried SB. Effect of CPAP on respiratory effort and dyspnea during exercise in severe COPD. J Appl Physiol (1985) 1990;69(1):179-188.

43. Dodd DS, Brancatisano T, Engel LA. Chest wall mechanics during exercise in patients with severe chronic air-flow obstruction. Am Rev Respir Dis 1984;129(1):33-38.

44. Martin J, De Troyer A. The behaviour of the abdominal muscles during inspiratory mechanical loading. Respir Physiol 1982;50(1):63-73. 